\title{
Economia plural e desenvolvimento territorial na perspectiva do desenvolvimento sustentável: Elementos teóricos de sociologia econômica e de socioeconomia*
}

Benoît Lévesque**

\section{Resumo}

O texto focaliza a contribuição que o conceito de economia plural oferece atualmente para o avanço das pesquisas sobre a viabilidade das dinâmicas territoriais de desenvolvimento sustentável. A primeira parte da linha de argumentação está centrada na clarificação do conceito de economia plural, com base nos estudos sobre a economia social e solidária, e sobre as propostas oriundas da Nova Sociologia Econômica e da socioeconomia dos territórios. Na segunda parte, o conceito de desenvolvimento sustentável é caracterizado sob o ângulo do chamado paradigma societal e das interações que ele mantém com o território e com a economia plural e social. Numa linha de crítica dos pressupostos da economia neoclássica, o autor acentua a necessidade de religar a economia a uma perspectiva ecológica e social mais ampla e de buscar respostas mais efetivas aos desafios colocados pela crise socioambiental planetária.

Palavras-chave: desenvolvimento territorial sustentável, economia plural, nova sociologia econômica, economia solidária, economia ecológica.

\section{Introdução}

Jo transcurso das últimas duas décadas, vêm se impondo cada 1 vez mais as intervenções e práticas econômicas derivadas dos enfoques de economia plural e de desenvolvimento territorial sustentável, especialmente nos domínios do desenvolvimento local e da economia social. Para os arquitetos dessas iniciativas, a redescoberta do ter-

* Tradução de Anne-Sophie de Pontbriand Vieira. Revisão Técnica de Paulo Freire Vieira.

*** Professor titular associado vinculado à Escola Nacional de Administração Pública (ÉNAP) e à Universidade do Quebec em Montreal (UQÀM). 
ritório no contexto do debate sobre desenvolvimento sustentável veio juntamente com a compreensão mais ou menos explícita do caráter plural da economia, fazendo com que esta última pudesse transcender as limitações das práticas estritamente mercantis e da racionalidade instrumental para integrar as dimensões e os fatores ditos extra-econômicos, como já havia sido sugerido anteriormente alguns economistas heterodoxos, como Polanyi, Boulding e Hirschman. Assumindo essa perspectiva, nosso texto compõe-se de duas partes distintas, mas complementares: a primeira está centrada no conceito de economia plural, que tentaremos delimitar a partir das pesquisas sobre a economia social e das principais contribuições teóricas da nova sociologia econômica (NSE) e da socioeconomia dos territórios; e a segunda focaliza o conceito de desenvolvimento sustentável, que examinaremos sob o ângulo do paradigma societal e das interações que ele mantém com o território e a economia plural e social.

\section{Economia plural e social}

Tentaremos elucidar o caráter plural da economia a partir de três conjuntos de contribuições teóricas: a contribuição dos estudos sobre a economia social e solidária, a da NSE e a da socioeconomia dos territórios. Apesar de todas essas contribuições dependerem de uma abordagem heterodoxa da economia, cada uma delas apresenta dimensões de análise relativamente específicas, mas que podem ser consideradas complementares.

\section{A contribuição das análises da economia social e solidária}

Os pesquisadores têm proposto várias definições do conceito de economia social, devido à multiplicidade de abordagens teóricas mobilizadas (LÉVESQUE \& MENDELL, 2005). Do mesmo modo, os poderes públicos, devido à diversidade de compromissos sociais forjados a partir de tais práticas, adotaram definições institucionais contrastadas segundo os territórios ou as dinâmicas sociais investigadas (LAVILLE, LÉVESQUE \& MENDELL2005). No entanto, todos eles concordam pelo menos em reconhecer que a economia social 
reúne via de regra os três componentes seguintes: as cooperativas, as mutuais e as associações que mantêm atividades econômicas (DEMOUSTIER, 2000; DESROCHE, 1983; DEFOURNY, 2005). Não questionaremos essas definições, a não ser o modo pelo qual algumas explicitam a dimensão plural da economia social. Sob esse ângulo, a economia social pode ser entendida de duas maneiras: como parte interessada numa economia mista, ou como constituída por uma pluralidade de princípios econômicos.

Com a publicação da obra de G. Fauquet intitulada Le secteur coopératif, em 1935, a idéia de um setor cooperativo funcionando no contexto de uma economia mista, que inclui também o setor capitalista e o setor público, foi se impondo gradativamente nos estudos cooperativos e, em seguida, nos estudos sobre a economia social. Essa idéia relativiza de certa maneira a utopia da "república cooperativa", segundo a qual a conquista, pelas cooperativas, do comercio, da indústria e, por fim, da agricultura nutria a expectativa de uma "cooperativização" do conjunto da economia (DRAPERI, 2000). Nos anos 1950, essa idéia de um setor cooperativo tornou-se tão evidente que acabou se estabelecendo, em áreas de interesse geral, um setor público complementar a um setor privado sempre dominante. Coube a C. Vienney (1980) dar sequiência à reflexão iniciada por Fauquet, mostrando que as cooperativas representam um setor claramente distinto dos dois outros por seus atores (relativamente dominados), suas atividades (necessárias, mas abandonadas pelo Estado e pelo mercado) e por suas regras (propriedade coletiva e sustentável, funcionamento democrático, distribuição dos excedentes segundo as atividades, dupla qualidade de membros e usuários). Posteriormente, o economista francês estenderá sua análise ao conjunto da economia social que aparece, assim, como parte de uma nova economia mista (VIENNEY, 1994). Nesse sentido, a economia de nossas sociedades não é totalmente capitalista, uma vez que nela podemos encontrar pelo menos dois outros setores econômicos que não são capitalistas.

As pesquisas mais recentes sobre a economia social e solidária, que emergiu no transcurso das duas ou três últimas décadas, mostram a ascensão de um terceiro setor que se inscreve no trinômio mercado-Estado-sociedade civil, cada vez mais reconhecido pelos 
poderes públicos (ANDION, SERVA \& LÉVESQUE, 2007; LÉVESQUE, 2005; LAVILLE, 1994; EVERS, 1998; PESTOFF, 1995). Essas pesquisas oferecem uma nova concepção da economia plural, ou seja, a de uma economia que se fundamenta na pluralidade de princípios e de recursos econômicos. Assim, essas iniciativas emergem via de regra a partir de um forte impulso no sentido da reciprocidade, especialmente o voluntariado e a doação, que dá consistência à associação voluntária. Mas para perenizar sua oferta de bens ou de serviços, essas iniciativas não podem limitar-se ao voluntariado, devendo mobilizar recursos oferecidos pelos poderes públicos, pelo fato de terem uma finalidade social, ou então dispor de recursos mercantis sem fins lucrativos. Dessa forma, a economia social e solidária depende duplamente de uma economia plural, ou seja, do ponto de vista de uma pluralidade de princípios (princípio da troca mercantil, princípio da reciprocidade e princípio da redistribuição) e também de uma pluralidade de recursos: recursos mercantis, recursos não-mercantis (ajuda financeira dos poderes públicos) e recursos não-mercantis e não-monetários (voluntariado).

Quadro 1: pluralidade econômica de recursos e de princípios

\begin{tabular}{|l|l|l|l|}
\hline & $\begin{array}{l}\text { Recurso mercantil } \\
\text { e princípio do } \\
\text { mercado }\end{array}$ & $\begin{array}{l}\text { Recurso não- } \\
\text { mercantil e princípio } \\
\text { redistribuição }\end{array}$ & $\begin{array}{l}\text { Recursos não- } \\
\text { mercantil e } \\
\text { não-monetário e } \\
\text { reciprocidade }\end{array}$ \\
\hline Coordenação & $\begin{array}{l}\text { Preço } \\
\text { (equivalente) } \\
\text { Horizontalidade e } \\
\text { sem obrigação }\end{array}$ & $\begin{array}{l}\text { Mandato, regras } \\
\text { Verticalidade e } \\
\text { obrigação (direito) }\end{array}$ & $\begin{array}{l}\text { Intercambio de } \\
\text { informação } \\
\text { Horizontalidade e } \\
\text { engajamento }\end{array}$ \\
\hline $\begin{array}{l}\text { Princípio de } \\
\text { regulação }\end{array}$ & Concorrência & $\begin{array}{l}\text { Coerção } \\
\text { (solidariedade fria) }\end{array}$ & $\begin{array}{l}\text { Cooperação } \\
\text { (solidariedade de } \\
\text { proximidade) }\end{array}$ \\
\hline Escolha & $\begin{array}{l}\text { 'on choisit avec } \\
\text { ses sous' }\end{array}$ & $\begin{array}{l}\text { Democracia } \\
\text { representativa }\end{array}$ & $\begin{array}{l}\text { Democracia } \\
\text { participativa }\end{array}$ \\
\hline Insatisfação & Exit* & Voice* & Loyalty* \\
\hline Racionalidade & Instrumental & Instrumental & Axiológica (em valor) \\
\hline
\end{tabular}

Lévesque a partir de Polanyi e Hirschman.

* Em inglês no original. 
A hibridação destes diversos recursos tendo em vista a articulação de um dado sistema produtivo e o estabelecimento de compromissos entre esses princípios plurais não são evidentes no plano da coordenação e das escolhas estratégicas (ver quadro 1). Entretanto, devido à sua finalidade social, à sua governança democrática e à sua vinculação com a propriedade coletiva, a economia social e solidária está institucionalmente melhor equipada do que todos os demais setores econômicos para alcançar uma hibridação desses diferentes recursos e estabelecer um compromisso entre as diversas lógicas de ação. Todavia, mesmo para a economia social e solidária isto não constitui uma tarefa evidente, uma vez que os modos de funcionamento podem variar consideravelmente em função das diferentes etapas de desenvolvimento, apesar da existência de um mesmo formato institucional (MALO et VÉZINA, 2004; MALO, 2001) Contudo, basta mostrar, por enquanto, como e porque os estudos sobre as empresas e organizações da economia social e solidária colocaram em evidência o caráter plural dessas atividades econômicas mais rapidamente do que aqueles realizados sobre outros tipos de empresas.

\section{A contribuição da nova sociologia econômica}

A Nova Sociologia Econômica (NSE) surge principalmente a partir do início dos anos 1980, na sequiencia da crise econômica e da "grande transformação" deflagrada alguns anos mais tarde (LÉVESQUE, BOURQUE e FORGUES, 2001; SWEDBERG, 1993). Ela mostra como os fenômenos econômicos são fenômenos sociais, a partir de pelo menos duas abordagens diferentes: uma delas centrada no indivíduo socialmente situado e no mercado entendido como forma organizacional, e a outra centrada nos atores coletivos e no mercado entendido como forma institucional.

\section{Do indivíduo socialmente situado à organização}

Para Granovetter (1985), que pode ser considerado como o líder da nova sociologia econômica nos Estados Unidos, a dimensão social da atividade econômica é constitutiva de toda ação econômi- 
ca. Sua crítica diz respeito menos à racionalidade instrumental do que à atomização e à sub-socialização do homo oeconomicus, agente sem estrutura; o que não o impede de criticar ao mesmo tempo o excesso de socialização de uma sociologia estruturalista que leva à dissolução do indivíduo nas estruturas sociais. As escolhas dos indivíduos estão relacionadas com as escolhas dos outros indivíduos, bem como com os vínculos pessoais prevalecentes nas redes. Diferindo de Polanyi no que diz respeito ao desacoplamento ${ }^{1}$ da economia que teria sido provocado pela regulação mercantil, Granovetter mostra que o mercado funciona adequadamente somente quando inserido em relações sociais, em redes cujas ligações fracas (por ex. profissionais) são tão importantes quanto as ligações fortes (por ex. familiares) devido à sua capacidade de construir pontes entre as diversas redes e de obter novas informações (GRANOVETTER, 1992). Embora mais preocupada com a dimensão cultural, a americana Zelizer (1994 e 1989) mostrou, entre outras coisas, que a moeda pode revestir uma pluralidade de formas, o que fica evidente no caso do uso da moeda no âmbito familiar. Em suma, tanto o dinheiro quanto o mercado podem ser considerados como socialmente enraizados e como realidades plurais, o que indica a pertinência de uma análise sociológica ou socioeconômica do núcleo duro da economia.

Do ponto de vista do Movimento Anti-Utilitarismo nas Ciências Sociais (MAUSS), a insersão social da economia pode ser evidenciada a partir do fenômeno do dom, tal como ele foi estudado pelo antropólogo Marcel Mauss (CAILLÉ, 1988 e 1997). Segundo esta abordagem, o dom revela como os objetos oferecidos podem expressar relações pessoais e, mais amplamente, o vínculo social. À diferença do intercambio mercantil, o dom nada exige em troca, mas procura manter ou conservar o vínculo social. Se, por um lado, o intercambio mercantil libera as partes de qualquer dívida, a doação, mesmo querendo ser um ato gratuito, cria uma obrigação - como demonstra o ciclo do dom e do contra-dom. Nessa perspectiva, "não se deve tentar entender o dom com base nos princípios de funcionamento das esferas mercantil ou estatal; ao contrário, devese procurar entender essas esferas procurando identificar aquilo que

1 Désencastrement no original. (Nota do Tradutor) 
fundamenta o dom, ou seja, partindo do ato de doar" (GODBOUT, 2000, p.8). Em outras palavras, o dom considerado como "fato social total" combina todas as dimensões da vida em sociedade: econômica, política, religiosa, imaginária, familiar etc. Sem dúvida, a sociabilidade do dom diferencia-se das lógicas abstratas e anônimas do Estado e do mercado mas, mesmo assim, infiltra-se nos seus interstícios de tal forma que continua a existir nas bases das sociedades modernas (GODBOUT, 1992, p.265). Mesmo que se possa questionar o projeto de reconstrução de uma outra abordagem da economia a partir do dom, o MAUSS não deixa de revelar uma dimensão importante da economia plural, ou seja, a presença da reciprocidade e a importância dos vínculos sociais no próprio âmago da economia de mercado (CAILLÉ, 2005, p.121).

A abordagem da economia das convenções, elaborada por economistas heterodoxos com a colaboração de sociólogos, mostra perfeitamente a pluralidade de mundos (lógicas de ação) que se tornam cités - ou formas de coordenação ou convenções - a partir do momento em que sua legitimidade passa a ser amplamente reconhecida como justificação (BOLTANSKI \& THÉVENOT, 1991). Esses pesquisadores identificaram inicialmente seis cités que correspondem a convenções historicamente construídas em torno de obras "grandiosas": convenção mercantil (ou ordem da concorrência), convenção industrial (ou ordem da eficiência), convenção cívica (ou ordem do coletivo), convenção doméstica ou interpessoal (ou ordem da confiança), convenção da inspiração (ou ordem da inovação), convenção de opinião (ou ordem do renome). Mais recentemente, um sétimo mundo, o mundo conexionista e uma sétima cité - a que opera por projetos - foram adicionados de forma a refletir as alterações recentes do capitalismo, em particular a expansão das redes (BOLTANSKI \& CHAPIELLO, 1999). Em princípio, esses vários mundos são familiares a todos os indivíduos, que os percorrem cotidianamente. Além do mais, eles também coexistem no âmbito de uma mesma organização, na qual os atores interagem, o que provoca, aliás, controvérsias e conflitos. Finalmente, a économie des grandeurs foi utilizada para explicar a complexidade da economia social, inclusive o fato de que ela implica um compromisso entre os diversos mundos: o mundo mercantil, o mundo cívico, o mundo doméstico (ENJOLRAS, 
1994). Numa visão ainda mais ampla, ela permite demonstrar que a economia, inclusive a capitalista, não pode ser reduzida ao mundo mercantil, já que este último coexiste com os outros mundos sem chegar a ser, às vezes, nem mesmo dominante.

\section{Dos atores individuais e coletivos às instituições}

Os "novos institucionalistas" anglo-americanos, que não devem ser confundidos com o neo-institucionalismo e seu líder, Williamson (1981), associam diversas correntes institucionalistas subsidiárias de uma socioeconomia das organizações e das instituições (HODGSON, 1988; HODGSON, SAMUELS \& TOOL, 1994). O renascer desta escola afirma-se principalmente no princípio dos anos $1980 \mathrm{com}$ Piore e Sabel (1984), cuja obra The Second Industrial Divide representa provavelmente uma das contribuições mais conhecidas desta corrente. Para esses dois economistas heterodoxos, a saturação da demanda por certos produtos de massa, aliada à procura pela qualidade, bem como a chegada de novas tecnologias e de instrumentos polivalentes constituem as premissas de uma dinâmica de especialização flexível, permitindo uma produção diversificada, uma requalificação do trabalho e novas formas de cooperação. A criação de novos mecanismos institucionais permite repensar a produção apostando em redes de pequenas empresas bem enraizadas no território, como podemos observar nos chamados distritos industriais italianos. A mudança do modelo de produção e de consumo abre um novo espaço onde os fatores extra-econômicos e os laços de cooperação entre empresas concorrentes representam novas vantagens competitivas.

Os evolucionistas, que integram a corrente dos institucionalistas em sentido amplo, consideram que a ciência econômica se inspira injustamente num modelo mecanicista, enquanto a biologia lhes parece mais apropriada para alimentar as dinâmicas econômicas (DOSI, 1991). Recuperando a contribuição de Schumpeter, esses economistas heterodoxos propõem conceitos úteis para o estudo das inovações, tais como o paradigma tecnológico, a trajetória tecnológica, e o sistema nacional ou regional de inovação (NELSON \& WINTER, 1982; FREEMAN, 1991; LUNDVALL, 1992; COOKE, 1998). O conceito de sistema de inovação, do qual faz parte a empresa inova- 
dora, permite mobilizar muitos recursos não-mercantis, a começar pela pesquisa universitária. Os evolucionistas, que analisam a dinâmica econômica em termos de ciclos longos, nem por isso hesitam em abrir a "caixa preta" das empresas para detectar as rotinas, as aprendizagens e as inovações dos agentes econômicos imbuídos de uma racionalidade limitada. Enfatizando a importância dos aspectos intencionais das mudanças tecnológicas, e introduzindo a idéia de inovação radical que provoca uma ruptura de paradigma produtivo, essa abordagem relativiza a noção de eficácia das técnicas, que se torna válida unicamente no âmbito de um dado paradigma (FREEMAN, 1991). Assim consideradas, as instituições podem tanto favorecer como bloquear a difusão das inovações, de modo que uma dada trajetória pode se revelar como indutora de relações de dependência, colocando em primeiro plano a discussão sobre opções políticas. Por último, é possível desenvolver estas análises visando considerar também as inovações sociais e mostrar como a economia social, na melhor das hipóteses, inscreve-se num sistema de inovação (LÉVESQUE, 2006, 2006a).

Os neo-corporatistas ${ }^{2}$, um grupo que integra principalmente os institucionalistas europeus, mostram-se interessados, entre outras coisas, pela concertação e por modalidades de coordenação das atividades econômicas efetivadas por meio de diferentes formas de governança (STREECK \& SCHMITTER, 1985). Assim, os fatores extra-econômicos e sociopolíticos tais como os bens coletivos e os bens públicos, incluindo-se aqui as instituições, são muitas vezes determinantes para a maior parte das atividades econômicas - notadamente na era da globalização, uma vez que podem representar a aquisição de vantagens comparativas (STREECK, 1992; MAZNER \& STREECK, 1991). Para a governança das atividades econômicas, os neo-corporatistas distinguem quatro formas ou ordens que combinam um princípio e uma instituição: (i) a concorrência dispersa e o mercado, (ii) a hierarquia e o Estado, (iii) a concertação organizacional e a associação, e (iv) a solidariedade espontânea e a

2 O qualificativo "neo-corporatista" provem do fato dos seus adeptos considerarem os atores coletivos e grupos de interesses presentes na democracia social e muitas vezes mobilizados para a construção de bens coletivos no contexto da concertação ou da parceria. 
comunidade (HOLLINGSWORTH, SCHMITTER \& STREECK, 1994). A distinção entre a forma comunitária e a forma associativa é particularmente relevante, pois evita que sejamos levados a confundir as governanças tradicionais que mesmo se apoiando no pertencimento à comunidade são frequientemente não voluntárias, com as governanças modernas baseadas na associação voluntária de pessoas. Vista dessa perspectiva, a democracia social pode complementar a democracia representativa, uma vez que favorece a deliberação entre indivíduos que representam interesses coletivos voltados para a construção de um bem comum, ou ainda um interesse geral que vai além dos interesses coletivos de tipo corporativo (SCHMITTER, 1992). Finalmente, essas análises continuaram a ser desenvolvidas por HOLLINGSWORTH \& BOYER (1997), que mostraram como o mercado e a hierarquia representam apenas duas modalidades de coordenação em meio a inúmeras outras igualmente importantes que recorrem ao engajamento, ou seja, a associação, as alianças, as redes, as comunidades, as parcerias etc.

Por último, a abordagem da regulação - que também faz parte do institucionalismo - nos estimula a considerar as instituições econômicas como resultantes de compromissos sociais firmados entre atores coletivos, sob o comando do Estado tendo em vista a sua institucionalização (AGLIETTA, 1976; BOYER, 1986). Assim, o mercado é visto essencialmente como uma instituição que pode assumir uma forma competitiva, como aconteceu no período de 1830 a 1929 , ou uma forma administrada, como foi o caso durante os Trinta Gloriosos (1945-1975). Portanto, a crise que emerge nos anos 1975 é realmente uma crise do binômio Estado-Mercado e não somente do Estado. Por outro lado, as mutações atuais parecem estar direcionadas no sentido de um trinômio Estado-MercadoSociedade Civil, cujo alcance pode ser tanto regressivo - como no modelo neo-liberal - quanto progressista - como nas sociedades que fazem da sociedade civil um parceiro efetivo das tomadas de decisão (BÉLANGER \& LÉVESQUE, 1991). Essa abordagem oferece também uma definição do modelo de desenvolvimento que permite integrar o conjunto das dimensões socioeconômicas, ou seja: um compromisso de amplo alcance entre grupos sociais no que se refere aos desafios estratégicos societais definidos pelo paradigma 
societal, um regime de acumulação mais ou menos intensivo, um modo de regulação que, sob a governança do Estado, reune de maneira coerente as diversas formas institucionais que garantem a compatibilidade da produção e do consumo, e uma inscrição na divisão internacional do trabalho entre os diferentes paises (LIPIETZ, 1989). Esta definição mostra a profundidade das mudanças que um modelo de desenvolvimento sustentável exigiria, a começar pela criação de um novo contrato social, depois por um regime de acumulação não-produtivista e por um modo de regulação, levando-se em conta as interdependências entre o local e o mundial.

\section{A socioeconomia e a sociopolítica dos territórios}

As análises do desenvolvimento territorial propostas, por um lado, pelos geógrafos e economistas heterodoxos e, por outro lado, pelos politólogos e os sociólogos, situam-se no prolongamento da sociologia econômica e das análises da economia social. Se os anos 1980 corresponderam à redescoberta do desenvolvimento local, os anos 1990 estão associados ao debate sobre o desenvolvimento territorial e sobre a entrada em cena do território e, em seguida, do desenvolvimento sustentável. Embora o conceito de território possa ser utilizado tanto em relação ao nível regional quanto ao nacional, ele tem sido cada vez mais utilizado para designar o nível local, referindo-se, por exemplo, aos efeitos de proximidade e aos regimes territoriais de governança.

\section{Os efeitos da proximidade geográfica e organizacional}

Guardando sintonia com a sociologia econômica, a economia de proximidade e o enfoque da regulação fornecem os elementos essenciais para definirmos o território do ponto de vista do desenvolvimento econômico. Como o território não constitui "um simples espaço delimitado de recursos”, mas uma construção social e histórica, nele podemos encontrar um sistema de atores (empresas, associações, organizações etc.) cuja articulação é assegurada por diversos tipos de proximidades num meio natural e que está orientado, entre outras, para atividades de produção e de consu- 
mo (BENKO, 2007, p.109; GILLY \& PECQUER, 1995, p.304; KLEIN \& FONTAN, 2004; FONTAN \& KLEIN, 2004). Esse sistema de atores, na medida em que está orientado para a promoção do desenvolvimento econômico, constitui também um sistema de ação e de mobilização de recursos que nos permite caracterizar vários tipos de desenvolvimento territorial.

A proximidade apresenta-se como "a primeira forma de interrelacionamento das atividades humanas" (BENKO et LIPIETZ, 2000, p.16). Três tipos de proximidades são identificados: (i) a proximidade geográfica, ou seja, a presença física num mesmo território; (ii) a proximidade organizacional, ou seja, as modalidades de coordenação, as convenções de identidade e de participação, os aprendizados e a acúmulo de conhecimento numa dada área; e (iii) a proximidade institucional, ou seja, as modalidades de regulação, as regulamentações e normas compartilhadas (COLLETIS, GILLY, LEROUX et al., 1999). Essas três formas de proximidade fornecem os elementos que nos permitem caracterizar três tipos de desenvolvimento territorial: o território de aglomeração (proximidade geográfica: acumulação e justaposição de atividades econômicas), o território de especialização (proximidade geográfica e proximidade organizacional: acumulação de conhecimentos numa área específica) e o território de especificação (proximidade geográfica, proximidade organizacional e proximidade institucional, que dotam o território de uma capacidade criativa para produzir recursos específicos relativamente a esses territórios) (PECQUEUR, 2000, p.99; DUPUY, GILLY \& LUNG, 2007; ZIMMERMANN, 2005). Com a globalização e o pós-fordismo, teríamos ingressado numa "nova idade dos territórios", (GUMUCHIAN \& PECQUEUR, 2007, p.17), "num novo paradigma de desenvolvimento denominado territorial” (BENKO, 2007, p. 105).

$\mathrm{O}$ modelo fordista caracterizava-se por sua indiferença relativamente à dimensão territorial, pois o modelo de produtividade preconizado pressupunha uma forma de concorrência fundada na diminuição dos custos e dos preços e numa separação entre produtores e consumidores, ou seja, num estilo de produção em massa onde não havia muita preocupação com a qualidade e a diversidade. Em consequiência, configurou-se uma divisão internacional do trabalho que colocava em oposição um conjunto de países formando um 
centro desenvolvido e um outro conjunto compondo uma periferia "sub-desenvolvida" (COURLET, 2007, p.34). A essa forma de território ao mesmo tempo uniforme e polarizado "se sucederia uma organização parcial e pontual (limitada no espaço, mas também no tempo) do território, com seus adensamentos (lugares com projetos múltiplos, implicando, portanto, a sobreposição de organizações territoriais) e seus espaços vazios (carentes de uma dinâmica de formulação e de capacidade de implementação de projetos)" (MOQUAY, 2005, p.99). Se o modelo de uma economia "contextualizada e territorializada" tende a se impor atualmente, a globalização incita duas lógicas opostas, mas indissociáveis: a lógica da deslocalização e das empresas nômades, em conformidade com uma lógica de firmas em busca de vantagens comparativas e de recursos genéricos (vantagens triviais como baixos salários ou isenções fiscais) e a lógica de uma economia do conhecimento e da qualidade ancorada no território e em busca de recursos específicos (dificilmente transferíveis, a exemplo da atmosfera industrial e de um alto nível de cooperação) e de vantagens diferenciadoras de acordo com uma lógica de territórios (PECQUEUR, 2007, p. 270). Em conclusão, os intercâmbios são efetivados doravante mais entre regiões do que mediante o recorte por sistemas produtivos nacionais, de tal forma que o território deixa de ser passivo. Por isso, existem dois tipos de oferta territorial: uma oferta concorrencial de vantagens genéricas e uma oferta de vantagens específicas relativas ao nível local.

Ao contrário da busca de vantagens comparativas, que caracterizavam o estilo de produção em massa, as vantagens diferenciadoras "são forjadas no processo (à montante) de elaboração de recursos não-mercantis constitutivos da natureza dos territórios (PECQUEUR, 2007, p.275; ZIMMERMANN, 2005). Deste ponto de vista, "a empresa mostra-se capaz e está interessada em forjar vínculos com outros atores, vínculos de natureza mercantil e nãomercantil", além de conseguir enraizar-se no território, indo além da proximidade geográfica para combinar a proximidade organizacional e a proximidade institucional (COLLETIS, GIANFALDONI \& RICHEZBATTESTI, 2005, p.12). Isso pode ser observado no caso da nova economia, "a economia mais avançada [que] funciona integrando o extra-econômico" e que atribui ao território um papel estratégico na 
conquista do mundo (VELTZ, 1996, p.11-12). Do mesmo modo, no coração das novas configurações espaciais, a exemplo da metropolização, "o território entra agora no jogo econômico como matriz de organização e de interações sociais, e não mais, em primeiro lugar, como estoque ou conglomerado de recursos técnicos" (VELTZ, 1996, p.10). Em conclusão, sem extinguir a concorrência mercadológica, os diferentes sistemas que dependem da economia dos territórios apóiam-se em grande parte na cooperação, na reciprocidade e na confiança, ou seja, num conjunto de dimensões sem preço e não especificamente mercantis (BENKO, 2007, p.111). Se a forte presença do extra-econômico permite uma abertura no sentido de uma economia plural ou mesmo de uma nova economia mista, deve-se ressaltar que aos poderes públicos passa a ser confiada uma nova missão para o desenvolvimento econômico.

\section{Governança territorial e economia social}

Para uma abordagem política integrada do desenvolvimento territorial, Itçaina, Palard e Ségas (2007) propõem o conceito de "regime territorial". Aplicado a uma "comunidade" territorial, este conceito "permite-nos elucidar as relações sociais e, portanto, as relações de poder consideradas dominantes no nível local; em termos de modalidades de elaboração de acordos locais, de coalisões público-privadas, de democracia versus autocracia ou hierarquia" (ITÇAINA \& PALARD, 2007, p.12). Este conceito recupera vários elementos convergentes com a definição de território formulada pelos economistas da proximidade e da regulação, ou seja: os atores, as organizações e as instituições, sem esquecer as representações e a cultura. Aplicado ao desenvolvimento territorial, o regime territorial permite "apreender algumas das dimensões constitutivas das novas modalidades da ação pública territorializada: a confiança entre atores, as modalidades de regulação sistêmica e a definição de problemas públicos", emergindo daí a necessidade "de articular e pensar juntos o território, os sistemas produtivos e a cultura" (ibid, p.13 et 15). Como resultado dos trabalhos realizados no contexto do CIRIEC Internacional (Centro Internacional de Pesquisa e Informações sobre a Economia Pública, Social e Cooperativa) 
sobre os regimes de governança (ENJOLRAS, 2005; BERNIER, BOUCHARD, LÉVESQUE, 2002; LÉVESQUE, 2002), podemos identificar um regime de governança territorial considerado mais favorável do que outros à economia plural. Trata-se do "regime em parceria", centrado na relação de parceria entre os atores privados, públicos e da sociedade civil, diferente do "regime concorrencial", que se baseia principalmente na concorrência e no mercado, e do regime público, que privilegia a administração pública e o setor público (e a antiga economia mista).

No que diz respeito à tipologia de estratégias possíveis de desenvolvimento territorial proposto pelos economistas da proximidade, pode-se presumir que o desenvolvimento territorial de aglomeração acomodar-se-ía a um regime territorial competitivo, até mesmo público, e o desenvolvimento territorial de especialização a um regime público, enquanto o desenvolvimento territorial de especificação exigiria um regime territorial de parceria para desabrochar. No contexto de uma modalidade de desenvolvimento territorial que busca valorizar recursos territoriais específicos e "mecanismos lentos da competitividade" tais como as competências, a conectividade, a solidariedade e a civilidade, a coesão social, a qualidade das relações e a confiança, "o Estado e as coletividades locais têm um papel fundamental a desempenhar nesses processos" (VELTZ, 1996, p.244). Entretanto, esse papel necessário dos poderes públicos não poderia ser assumido por uma política dirigista, e sim por políticas que favoreçam a criação de mecanismos territorializados, viabilizando as parcerias, a concertação e a participação dos vários atores sociais envolvidos (CÔTÉ, LÉVESQUE, MORNEAU, 2007). Focalizadas desta perspectiva, "as políticas de desenvolvimento territorial não oferecem as soluções para o problema, mas definem modelos interpretativos e espaços de concertação" (DE MAILLARD, 2000), modelos e espaços que são mobilizados pelos atores locais visando definir ao mesmo tempo o que pode ser considerado como problema e a solução a ser oferecida (SÉGAS, 2005, p. 343).

Dessa forma, a criação de recursos específicos e a constituição de um capital sócio-territorial que favoreçam a busca de transversalidade das várias intervenções não podem prescindir de uma forma de governança local que, por sua vez, irá reunir o conjunto das 
forças vivas da "comunidade" territorial para, eventualmente, fazer emergir um interesse geral em conformidade com este perímetro de solidariedade (MOUNIER \& THIRY, 1997; FONTAN \& KLEIN, 2004). Como forma de ação interacionista e deliberativa inscrita num horizonte de longo prazo, a governança favorece "a produção de conhecimentos na e para a ação" e gera "situações de aprendizagem e de revalidação cognitiva para atores que devem enfrentar um cenário de múltiplas incertezas e que se encontram inseridos em sistemas de interdependência” (PINSON, 2006, p.85). Além disso, a articulação de uma proximidade geográfica com uma proximidade organizacional e, a fortiori, institucional supõe uma governança local suscetível não só de definir projetos no sentido do interesse geral, mas também de assegurar a regulação e a resolução dos conflitos que, certamente, aparecerão depois dessa reunião de atores com lógicas plurais. Conseqüientemente, é necessário instaurar mecanismos apropriados que possibilitem a " combinação de uma rede de proximidades institucionais envolvendo atores-chave de diferentes tipos, privados e públicos, ou de estatuto diferente, dentre os quais estão incluídos os atores vinculados ao mundo associativo e cooperativo" (COLLETIS, GIANFALDONI \& RICHEZ-BATTESTI, 2005, p.13). É neste momento preciso que se questiona a contribuição específica da economia social e solidária ao desenvolvimento territorial tal como ele se apresenta na melhor das hipóteses.

Se a governança local tornou-se necessária e até mesmo essencial para assegurar a viabilidade de um estilo de desenvolvimento territorial sustentável, na verdade ela se tornou mais difícil de ser implementada do que antes. Atualmente, pode-se definir a situação local como a de "mais autonomia num ambiente mais difícil e mais restritivo em termos de interdependência" (LE GALÈS, 2006, p.9). Dentre as dificuldades encontradas na busca de concretização de sistemas de governança local, podemos destacar aquela que diz respeito à necessidade de articular atores muito diversificados (privados, públicos, associações, universidades, sociedades civis). Eles podem, a princípio, compartilhar apenas sua proximidade geográfica, a estivagem de diversas escalas de intervenção mais ou menos compartimentadas e a coordenação de lógicas de ação fortemente contrastadas (mercantil, hierárquica e associativa). Ou 
ainda a hibridação dos recursos mercantis, não-mercantis e não-monetários necessária ao funcionamento de uma "economia plural" e ancorada territorialmente, a exigência de articulação da democracia representativa e de vários registros de participação procedente da democracia participativa, sem esquecermos a questão da avaliação e da responsabilização. Em resumo, o grande desafio das políticas de desenvolvimento territorial é produzir coerência e transversalidade, criando "uma ligação horizontal entre diferentes categorias de ação pública verticais, como os setores (cultura, habitação, economia) ou as populações-alvo (jovens, desempregados, portadores de deficiência)" (SÉGAS, 2005, p.344). Para o enfrentamento da maior parte desses desafios, a economia social está melhor equipada, pelo menos institucionalmente, do que a maioria dos outros atores sócio-econômicos envolvidos na governança dos territórios.

Todavia, o desafio a ser enfrentado é considerável. Mesmo que o Estado queira se mostrar mais facilitador e estratégico do que antes, suas intervenções permanecem ainda excessivamente compartimentadas e verticalizadas. Por sua vez, as governanças locais são mais poli-governanças do que governanças unificadas, pelo fato de permanecerem parciais, limitadas, fragmentadas e disjuntas, muitas vezes apenas reproduzindo, "sob uma forma territorial, a especialização funcional própria dos segmentos político-administrativos do Estado" (EME, 2005, p.46). Por outro lado, a dependência da sociedade civil em relação ao Estado deve ser relativizada, pois as iniciativas socioeconômicas conseguem, frequientemente, ordenar as regulações públicas de controle a partir de projetos voltados para a promoção da autonomia, da inter-setorialidade ou mesmo da transversalidade - projetos capazes de gerar intervenções coerentes. Assim, aproximações poderiam ser estabelecidas entre as representações do interesse geral propostas pelos poderes públicos e aquelas relacionadas ao interesse coletivo construídas pela economia social e solidária. Considerada dessa perspectiva, a economia social e solidária realiza um duplo trabalho no plano da regulação: por um lado, ela negocia sua maneira de agir e seus projetos com os poderes públicos (Estado central, instancias regionais e locais) onde se encontram contradições, incertezas e ambivalências; por outro lado, ela realiza um "trabalho próprio", construindo "uma 
coerência territorializada específica por meio de um trabalho político do local sobre ele mesmo" (EME, 2005, p.45-46). Em síntese, no que diz respeito à governança e até mesmo à regulação local, a economia social e solidária fornece uma fonte de inspiração, provavelmente sub-explorada, não só para a ancoragem territorial de uma atividade econômica que não se restringe à mobilização de recursos mercantis, mas que leva em conta também a construção de uma economia plural a partir do território e de uma democracia aberta à participação dos cidadãos.

\section{O desenvolvimento sustentável e a economia plural}

O desenvolvimento sustentável foi definido pela Comissão Brundtland (1987) como um processo de desenvolvimento que "capaz de suprir as necessidades da geração atual, sem comprometer a capacidade de atender as necessidades das futuras gerações" (Commission mondiale sur l'environnement et le développement, 1988, p.10). Assim, o conceito de necessidade é colocado em relação estreita com o de limites. O programa normativo que resulta daí supõe uma "dupla solidariedade, uma solidariedade horizontal em relação aos mais necessitados do momento e uma vertical ou inter-geracional", o que implica "o tratamento de um conjunto de problemas sociais e ecológicos que passam a ser colocados tanto no nível nacional quanto no internacional" (MARÉCHAL, 2005, p.41). Dessa perspectiva, entende-se que o desenvolvimento sustentável exige um salto qualitativo não somente para o conjunto da economia, mas também para o desenvolvimento territorial e para a economia social tais como têm sido geralmente praticados.

\subsection{O paradigma do desenvolvimento sustentável: duas interpretações}

O paradigma do desenvolvimento sustentável é uma construção social e histórica que foi elaborada progressivamente ao longo de pelo menos três décadas. As primeiras expressões remontam aos anos 1960, com os novos movimentos sociais, entre eles os grupos ecológicos interessados em questionar o produtivismo e 
o consumismo em nome da qualidade de vida e dos valores pósmaterialistas (DELÉAGE, 2004, p.164; GOHORRA-GOBIN, 2000, p.133). Se o relatório Meadows (1972), Os limites do crescimento (The Limits to growth), e a primeira Conferência das Nações Unidas sobre Meio Ambiente (1972) representam outros tantos pontos de referência, a contribuição do economista Ignacy Sachs, promotor do ecodesenvolvimento, tornou possível a reflexão sobre um outro desenvolvimento, sem por isso romper com o crescimento, mas tentando "aproveitar os recursos potenciais do meio" para estabelecer um outro padrão de relacionamento com o ambiente (MARÉCHAL, 2005, p.38; 2005a, p.130). O choque do petróleo em 1974 e a crise econômica ofuscaram por um certo tempo a questão ambiental, mas essa última reapareceu nos anos 1980 com a poluição global provocada, por exemplo, pela redução da camada de ozônio e pelas chuvas ácidas. A tournée da Comissão Mundial sobre Meio Ambiente e Desenvolvimento de 1984 a 1987, a publicação do Relatório Brundtland e a criação do Grupo Intergovernamental de Especialistas sobre a Evolução do Clima (GIEC), em 1988, contribuíram sobremaneira para a sensibilização da opinião pública no que diz respeito à questão ambiental. Finalmente, com a Conferência das Nações Unidas sobre o Meio Ambiente e o Desenvolvimento, realizada no Rio de Janeiro em 1992, “o desenvolvimento sustentável adquire uma celebridade planetária” (MARÉCHAL, 2005, p.41).

Atualmente, o paradigma do desenvolvimento "acabou se impondo de maneira mais ou menos intensa aos atores políticos e econômicos sediados nos países industrializados" e igualmente nos países emergentes (SMOUTS, 2005, p.3). Nesse sentido, deixou de pertencer exclusivamente aos ecologistas, pois todos devem, doravante, se posicionar em relação a ele e argumentar sobre o sentido das atividades produtivas (GENDRON, 2005, p.225). Ou seja, mesmo que se admita a legitimidade do desenvolvimento sustentável, as interpretações sobre seu alcance "permanecem todavia abertas", inclusive as formas de solidariedade que isso implica (LAVILLE, 2005, p.340). Os conflitos suscitados pelo enfoque de desenvolvimento sustentável não são os do fordismo e tampouco do socialismo, na medida em que dizem respeito a uma outra matriz de desenvolvimento, um desenvolvimento que permitiria conjugar a conservação 
do meio ambiente e a promoção de níveis cada vez mais elevados de equidade social e geográfica. Sob esse ângulo, "o adversário é múltiplo" e desfigurado, pois "existe [inclusive] na mente de cada um de nós" (LIPIETZ, 1993, 10-11). Além disso, a modernização ecológica ultrapassa o contexto nacional para alcançar o nível das relações entre os países do Norte e do Sul. Como podemos observar, as convenções internacionais sobre o meio ambiente parecem ocasionar um "aumento da tensão entre países ricos e países pobres", devido notadamente ao fato de que as sociedades desenvolvidas consideram-se facilmente "protegidas frente à degradação do nosso mundo e à miséria da maioria dos seus habitantes" (DELÉAGE, 2005, p.84). Nesse contexto, tanto as análises como as tomadas de posição no que se refere ao desenvolvimento sustentável dão lugar a, pelo menos, duas interpretações ou discursos: uma versão forte, segundo a qual o desenvolvimento sustentável apresenta um conteúdo específico (substantivo), e uma versão fraca, segundo a qual o desenvolvimento sustentável é, em primeiro lugar, um recipiente, um meio sem conteúdo específico (procedural).

Para o discurso forte, o conteúdo específico é dado pela Conferência do Rio de 1992 e pela Agenda 21. Os princípios serão claros: prioridade às gerações futuras, à integração das três dimensões seguintes: o econômico (como meio), o social (como finalidade) e o ambiental (como condição) (GENDRON, 2005). Os princípios são hierarquizados, pois a preferência é concedida não somente ao longo prazo (sobre o curto prazo), por exemplo, "mas também às necessidades fundamentais não satisfeitas, às populações e às regiões mais vulneráveis e expostas às desigualdades, aos bens comuns e aos capitais mais críticos (como é o clima)" (THEYS, 2005, p.109). Visto desta perspectiva, o desenvolvimento sustentável não se reduz à integração do meio ambiente nas políticas setoriais: o conceito pressupõe a transversalidade, particularmente no que diz respeito à equidade e à integridade ecológica entendidas como condições ${ }^{3}$. Essa versão forte do desenvolvimento sustentável considera a economia como um meio ou instrumento "voltado para a

3 Ver o site da Chaire de responsabilité sociale et de développement durable : www.ceh. uqam.ca 
promoção das finalidades ligadas à justiça social e à sustentabilidade ecológica, cujo teor resulta de uma deliberação política" (LAVILLE, 2005, p.336). Logo, não se pode mais levar em conta exclusivamente a rentabilidade financeira; impõe-se o apelo a outros critérios, tais como a durabilidade, a qualidade de vida, a reciprocidade, a criação de empregos etc. Ou seja, "um desenvolvimento sustentável, na versão da sustentabilidade forte, só se torna traduzível em avanços concretos por meio dofortalecimento das esferas não-mercantis e não-monetárias articuladas a mercados regulados" (ibid., p.337). Como podemos perceber, a versão forte do desenvolvimento sustentável tende a ampliar o campo do extra-econômico, da economia plural e até mesmo da economia mista.

Por outro lado, a versão fraca do desenvolvimento sustentável apóia-se numa definição da economia mais formal do que substantiva: o capital natural (a exemplo dos recursos naturais) e o capital técnico são substituíveis - "o desaparecimento de uma parte do primeiro pode ser facilmente compensado por um aumento do volume do segundo" -, o mecanismo do mercado permite essa substituição de tal maneira que existiria "um ritmo otimizável de destruição da natureza” (MARÉCHAL, 2005, p.44). A combinação do mecanismo do mercado e da capacidade de auto-regulação das empresas permitiria à economia responder às exigências da sustentabilidade assim entendida. Assim, "a economia neoliberal pode apropriar-se do desenvolvimento sustentável somente mutilando-o e desnaturando-o", especialmente ao reduzir as três esferas - o social, o meio ambiente e a economia - a essa última, entendida exclusivamente como esfera mercantil (PASSET, 2005, p.421). Em razão do seu modo de propriedade e pelo fato de obedecerem a vários princípios econômicos, as empresas públicas e de economia social parecem, então, usufruir de privilégios indevidos. Deveriam, portanto, alinhar-se com o mercado ou, pelo menos, reduzir suas atividades de prestação de serviços públicos aos mais necessitados e às associações com perfil caritativo (LAVILLE, 2005, p.334). Finalmente, essa versão do desenvolvimento sustentável tende a promover uma solidariedade filantrópica que parte da empresa mais do que da sociedade (uma solidariedade sem reciprocidade onde a pessoa ajudada torna-se devedora do doador), em detrimento das 
duas outras formas de solidariedade democrática (o Estado Providência e a economia social) que se apóia na igualdade de direitos e na reciprocidade. Em suma, essa abordagem do desenvolvimento tende a restringir o campo do extra-econômico, da economia plural e da economia mista.

\subsection{Desenvolvimento territorial e economia social: rumo a um desenvolvimento sustentóvel}

Se a economia social e o desenvolvimento territorial (entendido como desenvolvimento local) são favorecidos no contexto de uma versão forte do desenvolvimento sustentável, a questão que se coloca agora é saber como ambos contribuem para a consolidação dessa versão. Como já sugerimos anteriormente, a economia social e o desenvolvimento territorial compartilham várias características com o desenvolvimento sustentável. Mais explicitamente, podemos ressaltar em primeiro lugar sua abertura à criação de uma economia plural e de um paradigma econômico diferente daquele proposto pelos economistas neo-clássicos mais ortodoxos (GAGNON, 2005, p.211). Em segundo lugar, observamos dos dois lados uma grande preocupação com a transformação da economia, o que encoraja a elaboração de abordagens explicativas que adotam espontaneamente perspectivas normativas. Em terceiro lugar, as parcerias, a participação dos cidadãos, a governança aberta às partes recebedoras, a democracia participativa e a preocupação com a transversalidade são vistas como necessárias e incontornáveis tanto para o desenvolvimento territorial e a economia social como para o desenvolvimento sustentável. Finalmente, a equidade, a qualidade de vida, o capital social e a atenção concedida às desigualdades são comuns aos três.

Apesar dessas convergências, nem todas as dimensões do desenvolvimento sustentável e, sobretudo, sua hierarquização e integração conforme a visão forte são necessariamente consideradas pelos enfoques de desenvolvimento territorial e de economia social. Primeiramente, a proposta de equidade em relação às gerações futuras, e entre o Norte e o Sul, nem sempre é respeitada, em contraste com o enfoque de desenvolvimento sustentável na sua versão forte. Em segundo lugar, os adeptos do desenvolvimento territorial e da 
economia social colocam em foco "as comunidades e coletividades territoriais entendidas como atores centrais do desenvolvimento", enquanto os adeptos do desenvolvimento sustentável adotam perspectivas "mais políticas do que territoriais, mais internacionais do que locais" (GAGNON, 2005, p.212). Em terceiro lugar, a consideração da dimensão socioambiental é muito mais explícita e, sobretudo, mais central no enfoque de desenvolvimento sustentável do que nos de desenvolvimento territorial e de economia social. Em quarto lugar, o nível de integração das dimensões sociais, econômicas e ambientais, assim como a transformação necessária dos modos de produção e de consumo ultrapassam claramente os enfoques de desenvolvimento territorial e de boa parte da economia social. Por fim, os objetivos do programa de ação associado ao enfoque de desenvolvimento sustentável são muito mais precisos e exigentes, e as ferramentas propostas mais complexas e rigorosas, a exemplo do programa de ação 21 (Agenda 21). Em resumo, a economia social e o desenvolvimento territorial devem realizar um salto qualitativo, tanto no plano do conteúdo como no do rigor da abordagem, no intuito de contribuir para a consolidação de uma versão forte do enfoque de desenvolvimento sustentável.

A pertinência das coletividades locais para o desenvolvimento sustentável impõe-se se considerarmos que delas dependem várias áreas de importância decisiva para a conservação do meio ambiente e para a promoção da qualidade de vida das populações, a exemplo do transporte, da habitação, da gestão do lixo e da reciclagem, do urbanismo e do ordenamento territorial, sem esquecermos a integração social e a participação cidadã. Alem disso, estima-se que aproximadamente "dois terços das emissões de gás estufa, causadas pelo aquecimento das habitações e pelos transportes, dependem de setores onde as coletividades podem intervir" (MOUSSEL, 2007, p.135). Nesse sentido, a "preocupação com o ambiente pode ser interpretada também como um meio de reforçar o local num contexto globalizado" (GOHORRA-GOBIN, 2000, p.147). Mas a complexidade do processo de concretização das estratégias de desenvolvimento sustentável, tal como o tema é focalizado na Agenda 21 Local, pode constituir um obstáculo à sua difusão em larga escala. Na escala mundial, estima-se que existam apenas 6.400 experiências em 113 
países inscritas no inventário de Agendas 21 locais, de acordo com o relatório elaborado em 2001 sob a orientação do International Council for Local Environmental Initiatives (ICLEI) (ver http://www.iclei.org/iclei. htm). A Agenda 21 a nível local representa portanto um movimento importante, mas que corresponde a um volume de apenas 56 projetos, em média, por país fornecedor de informações sobre o assunto.

Além disso, considerando somente os países do Norte, análises parciais sugerem que a difusão da Agenda 21 vem ocorrendo de maneira desigual - segundo os países e até mesmo no interior de um mesmo país. Assim, no contexto europeu a sua adoção, no nível local, tem sido alcançada de maneira mais rápida e mais ampla na Europa do Norte, nos Países Baixos e na Alemanha, enquanto outros países como a França ${ }^{4}$ revelam um atraso significativo neste sentido (CHARLOT, 2007, p.9). Nos Estados Unidos, as iniciativas voltadas para o desenvolvimento sustentável são maiores nas regiões do sudeste, sudoeste e noroeste do que no centro-sul do país (CHEVALIER, 2005, p.217). Do mesmo modo, o Canadá, e particularmente o Quebec, acumularam um atraso considerável no que se refere à promoção do enfoque de desenvolvimento sustentável (GAGNON, 2005, p.205; GAGNON \& ARTH, 2007). Finalmente, tanto nos países europeus como nos Estados Unidos e no Canadá, a questão do desenvolvimento territorial sustentável tem sido levantada cada vez mais a partir das cidades, o que de forma alguma nos surpreende, pois elas "estão no comando dos modos de produção e de consumo e são também a principal fonte de problemas ecológicos, seja sofrendo-os ou impondo-os" (EMELIANOFF, 2005, p.205).

Quanto à economia social, sua contribuição para o desenvolvimento sustentável, na sua versão forte, requer também un salto qualitativo, especialmente no que ser refere à questão ecológica e ambiental. Para as empresas de economia social, este compromisso é feito muitas vezes a partir da responsabilidade social das empresas $^{5}$ (RSE), tanto mais que essa responsabilidade "aparece

4 Na França, podemos encontrar apenas 216 Agendas 21, envolvendo 16 regiões, 29 províncias, 61 inter-municipalidades, 106 cidades e 4 parques naturais (CHARLOT, 2007, p.9). É pouco, se considerarmos que a França tem 36000 municípios. Ver também o site www.agenda21france.org.

5 Sobre a responsabilidade social e da ética, ver entre outros Salmon (2007), 
hoje como a tradução microeconómica mais visível do desenvolvimento sustentável" (SAINTENY, 2005, p.202). Com efeito, em termos de gestão, a RSE pressupõe hoje em dia a tríplice prestação de contas (econômica, social e ambiental) e a participação cidadã (PASQUERO, 2005, p.118; TURCOTTE \& SALMON, 2005; SALMON, 2007). Segundo a abordagem do desenvolvimento sustentável, a empresa passa a ser assim avaliada do ponto de vista das externalidades sociais e ambientais, de sua contribuição à qualidade de vida, à conservação e à minimização dos riscos (GENDRON, 2007). Por fim, cada vez mais as empresas capitalistas e mesmo as pequenas e médias empresas (PME) percebem que os custos da responsabilidade social podem ser inferiores aos da irresponsabilidade. Devido aos seus formatos institucionais, que fazem da economia um meio para o alcance de finalidades sociais, as empresas da economia social sentiram-se a princípio menos visadas pela exigência de RSE, esquecendo que essa última podia convidá-las a novos compromissos, incluindo o da integridade ecológica.

Como para o desenvolvimento territorial pensado a partir da Agenda 21 Local, a complexidade dos mecanismos de avaliação da RSE pode se tornar um freio à sua disseminação e à sua aplicação. Esta complexidade torna-se visível na maior parte dos procedimentos de RSE e nos princípios que devem orientá-los. É o caso da Global Reporting Initiative (GRI) ${ }^{6}$, que propõe uma grade de avaliação, e do Global Compact, que fornece os valores e os princípios associados ao desenvolvimento sustentável (PASQUERO, 2005, p.127). Algumas empresas da economia social, sobretudo no setor financeiro, passaram a se engajar em processos de RSE.

No relatório que produziram em 2005, os bancos cooperativos europeus admitem que estão plenamente ajustados à démarche de responsabilidade social das empresas, devido à sua identidade e às suas atividades, à sua governança democrática, à sua contribuição

Turcotte e Salmon (2005) e Gendron (2006). Ver também o site da Chaire de responsabilité sociale et de développement durable :http://www.crsdd.uqam.ca, sem esquecer seu boletim, Oeconomia Humana : http:/www.crsdd.uqam.ca/ publication/?page $=$ bulletinOH.

6 Em inglês no original e ver www.globalreporting.org/GRIPortal/GRICcontrols/ G3Online/ 
para o desenvolvimento sustentável a nível local, ao seu investimento social e ecologicamente responsável, à sua participação em sistemas de micro-crédito, de reinserção social e de cooperação e, por último, à promoção da cidadania responsável, de obras filantrópicas e do patrocínio cultural (European Associoation of Cooperative Banks, 2005). Num estudo académico recente focalizando a nova etapa do cooperativismo e o desenvolvimento sustentável (GIJSELINCKX, DELVETERE et RAYMAEKERS, 2007) mostram que a retomada do primeiro, enfatizando a implicação mais intensa dos participantes e uma renovação do leque de produtos ofertados, tem ocorrido frequentemente em estreita vinculação com a abordagem de desenvolvimento sustentável. No Quebec, o FondAction para a cooperação e o emprego (CSN) (2007) acabou de concluir o seu primeiro relatório de atividades voltadas para o desenvolvimento sustentável, de acordo com as diretrizes da GRI e está empenhado em produzir relatórios com este perfil a cada dois anos.

No campo da economia social, parece mais fácil às empresas que operam no setor financeiro de assumirem explicitamente sua inserção numa démarche certificada de responsabilidade social baseada no enfoque de desenvolvimento sustentável. Diante da complexidade dos processos de concessão de crédito do tipo GRI, pode-se perguntar se as pequenas empresas da economia social, inclusive aquelas que atuam em conformidade com os princípios do desenvolvimento sustentável, estão habilitadas a fazer essas avaliações. Alem disso, existem cada vez mais empresas da economia social que prestam serviços relacionados à questão do meio ambiente, seja na área de consultoria, da reciclagem, da produção orgânica, do financiamento ecológico ou do comercio justo, entre outras. Portanto, parece possível pensar que a filosofia do desenvolvimento sustentável esteja penetrando cada vez mais a economia social e que esta poderia se tornar muito "naturalmente" uma especie de "vanguarda" do desenvolvimento sustentável. Todavia, implica que ela deverá efetuar uma reavaliação da sua missão estratégica, cujos princípios norteadores foram definidos na época da primeira revolução industrial. Não resta dúvida que os utopistas do século 19 responsáveis pela idéia de uma economia social levaram em conta a necessidade de um outro padrão de relacionamento com a natureza, 
a começar pela relação campo-cidade, mas sua crença nas virtudes do progresso técnico acabou não sendo devidamente questionada.

\section{Conclusão}

Nossa definição de partida da economia plural foi extraída das pesquisas sobre a economia social e solidária que problematizaram essa noção mostrando que esse setor, em consequencia de seus princípios e de suas regras, baseava-se numa pluralidade de recursos económicos (mercantis, não-mercantis e não-monetários) e numa pluralidade de lógicas de ação, inclusive numa racionalidade axiológica. Em seguida, examinamos varias contribuições da nova sociologia econômica (NSE) e da socioeconomia dos territórios, que mostram que a economia como um todo é social, até mesmo plural, não somente pelo seus inputs e seus outputs mas também pelo fato do próprio mercado constituir uma forma institucional e uma forma organizacional - que são outras tantas construções sociais. Além disso, a coordenação das atividades econômicas e a circulação dos bens são realizadas por meio do mercado e da hierarquia, mas também de modalidades de governança baseadas no compromisso social, como acontece nas associações, nas redes, nas alianças, nas comunidades e coletividades de todo tipo. Do mesmo modo, as análises do território em termos de proximidade e de oferta territorial, com base em vantagens não transferíveis, deixam perceber a importância do enraizamento social, da qualidade das relações e, mais amplamente, dos fatores extra-econômicos e não-mercantis. Em suma, tanto em termos de recursos mobilizados (recursos mercantis e não-mercantis ou não-monetários) quanto das lógicas de ação, das modalidades de coordenação e dos modos de regulação, sem esquecer a relação com o território, a economia no seu conjunto (ou seja, incluindo a capitalista) não é apenas social mas também plural.

O paradigma do desenvolvimento sustentável propõe que devemos repensar as relações não apenas entre a economia (para fazer dela um meio) e o social (para fazer dela uma finalidade), mas também com a integridade ecológica entendida como uma condição incontornável. Além disso, este paradigma amplia as formas de solidariedade com os mais necessitados hoje em dia e também 
com as gerações futuras, de modo que a redução das desigualdades sociais e geográficas (principalmente entre o Norte e o Sul) representa outro item prioritário. Essa versão do desenvolvimento sustentável oferece à economia plural um espaço historicamente inédito em termos de amplitude, enquanto a versão fraca concederia com prazer uma exclusividade relativa à auto-regulação mercantil, questionando assim tanto a economia social e solidária quanto um estilo de desenvolvimento territorial que pretende ser sustentável. Se existe realmente uma convergência entre o desenvolvimento sustentável, por um lado, e o desenvolvimento territorial e a economia social e solidária, por outro lado, os desafios são aparentemente mais importantes do que se poderia esperar inicialmente. É o que revelam, entre outros, os territórios e as empresas vinculadas à economia social que decidem inscrever-se mias sistematicamente e mais rigorosamente em démarches certificadas de desenvolvimento sustentável. Os quadros institucionais da economia social, por exemplo, que apresentam uma solidez superior aos compromissos voluntários da responsabilidade social das empresas (RSE) e da Agenda 21, poderiam ser complementadas com credenciamentos oferecidos por outras organizações além das estatais para dimensões parcialmente redefinidas e ainda não institucionalizadas (o que não significa que os poderes públicos devam permanecer passivos nesse campo). Finalmente, o que nos parece mais importante diz respeito à constatação de que o desenvolvimento sustentável nos convida não somente a agregar a dimensão ambiental às dimensões sociais e econômicas, mas também a repensar o conteúdo de cada uma dessas dimensões.

Recebido em 20.11.2008

Aprovado em 10.1.2009

\section{Referências}

AGLIETTA, M. Régulation et crises du capitalisme. L'expérience des États-Unis. Paris: Calmann-Lévy, 1976.

ANDION, C.; SERVA, M. \& LÉVESQUE, B. O debate sobre a economia plural e sua contribuição para o estudo das dinâmicas de desenvolvimento territorial sustentável. In: Eisforia, Numero 
especial: Desenvolvimento territorial sustentável: Conceitos, experiências e desafios teórico-metodológicos, Ano 4 - Vol. 4, Dezembro 2006.

BÉLANGER, P.R. \& LÉVESQUE, B. La théorie de la régulation, du rapport salarial au rapport de consommation. Un point de vue sociologique. Cahiers de recherche sociologique, no 17, p. 17-52, 1991.

BENKO, G. Territoires et sciences sociales. In: ITÇAINA, X., PALARD, J. \& S. SÉGAS (Dir.) Régimes territoriaux et développement économique. Rennes: Presses Universitaires de Rennes, 2007.

BENKO, G. \& LIPIETZ, A. Géographie socio-économique ou économie géographique. In: BENKO, G. \& LIPIETZ, A. (Dir.). La richesse des régions: la nouvelle géographie socio-économique. Paris: PUF, 2000.

BENKO. G. \& LIPIETZ, A. (Dir.). Les régions qui gagnent. Paris: PUF, 1992.

BERNIER, L.; BOUCHARD, M \& LÉVESQUE, B. La prise en compte de l'intérêt général au Québec. Nouvelle articulation entre l'intérêt individuel, collectif et général. In: ENJOLRAS, B. \& von BERGMANNWINBERG, M-L. (Dirs.) Économie plurielle et régulation socioéconomique/Plural Economy and Socio-Economic Regulation. Liège: CIRIEC-International, 2002.

BOLTANSKI, L. \& THÉVENOT, L. De la justification. Les économies de la grandeur. Paris: Éditions Gallimard, 1991.

BOLTANSKI, L. \& CHIAPELLO, E. Le nouvel esprit du capitalisme. Paris: Éditions Gallimard, 1999.

BOYER, R. La théorie de la régulation: une analyse critique. Paris: La Découverte, 1986.

CAILLÉ, A. Dé-penser l'économique. Contre le fatalisme. Paris: La Découverte, 2005.

CAILLÉ, A. Don, association et solidarité. Revue internationale de l'économie sociale, n.265, 1997.

CAILLÉ, A. Critique de la raison utilitaire. Paris: La Découverte, 1988.

CHARLOT, A. Une forte progression depuis Johannesburg. In: Développement durable, villes, régions, agir localement. Alternatives Économiques. Hors-Série Pratique, No 29, 2007. 
CHEVALIER, J. Quels contenus aux politiques de développement durable des villes aux Etats-Unis?. MARÉCHAL, J-P. \& QUENAULT, B. (Dir.) Le développement durable. Une perspective pour le $\mathrm{XXI}^{\mathrm{e}}$ siècle. Rennes: Presses Universitaire de Rennes, 2005.

COLLETIS, G.; GIANFALDONI, P; \& RICHEZ-BATTESTI, N. Économie sociale et solidaire, territoires et proximité. Revue internationale de l'économie sociale (RECMA), No 226.

COLLETIS, G.; GILLY, J-P.; LEROUX, I. et al. Construction territoriale et dynamique économique. In: Sciences de la Société, No 48, octobre 1999, 1999.

COMMISSION MONDIALE SUR L'ENVIRONNEMENT ET LE DÉVELOPPEMENT. Our Common Future. Oxford: Oxford University Press (Traduction française: Notre avenir à tous. Montréal: Les Éditions du Fleuve) (Rapport Brundtland), 1987.

COOKE, P. Introduction. Origins of the concept. In: BRACZYK, H.-J.; COOKE, P. \& HEIDENREICH, M. (Dir.) Regional Innovation Systems. The role of governances in a globalized World, London et New York: Routledge, 1998.

CÔTÉ, L; LÉVESQUE, B. \& MORNEAU, G. Lévolution du modèle québécois de gouvernance. Le point de vue des acteurs. Politique et Sociétés, Vol. 26 no 1, 2007.

DEFOURNY, J. Économie sociale. In: LAVILLE, J-L. \& CATTANI, A. (Dir.). Dictionnaire de l'autre économie. Paris: Desclée de Brouwer, 2005.

DEMOUSTIER, D. Léconomie sociale et solidaire et le développement local. In: CHOPART, J.N.; NEYRET, G. \& RAULT, D. (Dir.). Les dynamiques de l'économie sociale et solidaire. Paris: La Découverte (Coll. Recherches), 2006.

DELÉAGE, J-P. Paradoxe du développement durable. In: MARÉCHAL, J-P. \& QUENAULT, B. (Dir.) Le développement durable. Une perspective pour le XXIe siècle. Rennes: Presses Universitaire de Rennes, 2005. DELÉAGE, J-P. Écologistes et alternatifs. In: Écologie \& politique. No 28, 2004.

DE MAILLARD, J. Le partenariat en représentation: contribution à l'analyse des nouvelles politiques sociales territorialisées. Politiques et management public. Vol. 18, no 3, 2000. 
DESMOUSTIER, D. Les organisations d'économie sociale, acteur de la régulation socio-économique, Revue internationale de l'économie sociale, Paris, No 275-276, 2000.

DESROCHE, H. Pour un traité d'économie sociale. Paris: Coopérative d'édition et d'information mutualiste, 1983.

DOSI, G. Perspective on Evolutionary Theory. Science and Public Policy, Vol. 18 no 6, 1991.

DRAPERI, J.-F. Léconomie sociale face à un siècle de pratiques coopératives. Revue internationale de l'économie sociale (RECMA), No 275-276, 2000.

DUPUY, Y., GILLY, J.-P. \& LUNG, Y. De l'analyse sectorielle à l'analyse territoriale : pour une approche méso-économique. In: ITÇAINA, X.; PALARD, J. \& SÉGAS, S. (Dir.) Régimes territoriaux et développement économique. Rennes: Presses Universitaires de Rennes, 2007.

EME, B. Gouvernance territoriale et mouvements d'économie sociale et solidaire. Revue internationale de l'économie sociale (RECMA), No 296, 2005.

EMELIANOFF, C. L'urbanisme durable en Europe: à quel prix?. MARÉCHAL, J.-P. \& QUENAULT, B. (Dir.) Le développement durable. Une perspective pour le $\mathrm{XXI}^{\mathrm{e}}$ siècle. Rennes: Presses Universitaire de Rennes, 2005.

ENJOLRAS, B. Vers une théorie socio-économique de l'association: l'apport de la théorie des conventions. In: Revue des études coopératives, associatives et mutualistes (RECMA), No 48, 1994.

. Économie sociale et solidaire et regime de gouvernance. Revue internationale de l'économie sociale (RECMA), no 296, 2005.

EUROPEAN ASSOCIATION OF CO-OPERATIVE BANKS. La responsabilité sociale des enterprises. Les activités des banques cooperatives, Groupement européen des banques cooperatives (document disponible: www.eurocoopbanks.coop), 2005.

EVERS, A. Part of Welfare Mix: The Third Sector as an Intermediate area. Voluntas, 6 (2), 1995.

FONTAN, J-M e J-L. KLEIN. La mobilisation du capital socio-territorial : le cas du technopôle Angus, Lien social et Politiques-RIAC, no 52, 2004. 
FREEMAN, C. Innovation, Change of Techno-Economic Paradigm and Biological Analogies in Economics, Revue économique, no 2, mars, 1991. GAGNON, C. Développement durable et viable : enjeux sociaux et scientifiques. In: LAFONTAINE, D. \& JEAN, B. Territoires et fonctions. Tome 1: Des politiques aux théories: Les modèles de développement régional et de gouvernance en débats. Rimouski: Éditions du GRIDEQ et Édition du CRDT, 2005.

GAGNON, C \& ARTH, E. Les acteurs de l'Agenda 21e siècle local et leurs principaux rôles. Identifier les acteurs selon les temps de la démarche. Dans GAGNON, C. (Éd) \& ARTH, E. (en collab. avec). Guide québécois pour des Agendas 21e siècle locaux: applications territoriales de développement durable viable, 2007. [En ligne] http:// www.a21l.qc.ca/9573_fr.html.

GENDRON, C. Le Québec à l'ère du développement durable. Options politiques/Policy Options, Juillet-Août, 2005.

. Économie de l'environnement, économie écologique et sociologie économiquye de l'environnement : la nécessaire prise en compte des dimensions socialement construires du système économique et de la crise écologique. In: GENDRON, C. \& J.-G. VAILLANCOURT (Dir.) Environnement et sciences sociales. Les défis de l'interdisciplinarité. Québec: Presses de l'Université Laval, 2007.

GIJSELINCKX, C., DEVELTERE, P.e P. RAYMAEKERS (2007), Renouveau coopératif et développement durable, Leuven, Hoger Instituut voor de arbeid (Katholieke Universiteit Leuven).

GILLY, J.-P. \& PECQUEUR, B. La dimension locale de la régulation. In: R. BOYER e Y. SAILLARD (Dir.) Théorie de la régulation. Létat des savoir. Paris: La Découverte, 1995.

GODBOUT, J.T. (en collaboration avec A. Caillé). L'esprit du don. Paris: Éditions La Découverte, 1992.

. Le don, la dette et l'identité. Homo donator vs homo oeconomicus, Montréal, Boréal, 2000.

GOHORRA-GOBIN, C. Les Etats-Unis entre le local et le mondial, Paris, Presses de Science Po.

GRANOVETTER, M. Economic Action and Social Structure: The Problem of Embeddedness, American Journal of Sociology, 1985. 
. Problems of explanation in economic sociology. In: NOHRIA, N. \& ECCLES, R.G. (Dir.) Networks and Organizations: Structure, Forme and Action, Boston, Harvard Business School Press, 1992.

GUMUCHIAN, H. \& PECQUEUR, B. (Dir.) La ressource territoriale. Paris: Anthropos, 2007.

HODGSON, G. M. Economics and Institutions. A Manifesto for a Modern Institutional Economics. Philadelphia: University of Pennsylvania Press, 1988.

HODGSON, G.; SAMUELS, W.J. \& TOOL, M.R. The Elgar Companion to Institutional and Evolutionary Economics. Aldershot: Edward Elgar, 2 tomes, 1994.

HOLLINGWORTH, J.R. \& BOYER, R. (Dir.) Contemporary Capitalism. The Emdeddedness of Institutions. Cambridge: Cambridge University Press, 1997.

ITÇAINA, X. Le territoire entre ressource et contrainte. Économie sociale et économique identitaire en pays basque français. In: AMINTAS, A.; GOUZEN, A. \& PERROT, P. (Dir.). Les chantiers de l'économie sociale et solidaire. Rennes: Presses universitaires de Renne, 2007.

ITÇAINA, X., PALARD, J. \& SÉGAS, S. (Dir.) Régimes territoriaux et développement économique. Rennes: Presses Universitaires de Rennes, 2007.

ITÇAINA, X. et PALARD, J. Introduction: Culture, territoire, systèmes productifs. In: ITÇAINA, X., PALARD, J. \& SÉGAS, S. (Dir.) Régimes territoriaux et développement économique. Rennes: Presses Universitaires de Rennes, 2007.

KLEIN, J.-L. \& FONTAN, J.M. (Dir.) Innovation sociale et territoire. Géographie, Économie, Société, vol. 6, no 2. Paris: Lavoisier, 2004.

LAVILLE, J.-L. Solidarité et développement durable. In: MARÉCHAL, J.-P. \& QUENAULT, B. (Dir.). Le développement durable. Une perspective pour le XXIe siècle. Rennes: Presses Universitaire de Rennes, 2005.

LAVILLE,J.-L. (Dir.) Léconomie sociale, une perspective internationale. Paris: Desclée de Brouwer, 1994. 
LAVILLE, J.-L., LÉVESQUE, B. \& MENDELL, M. The Social Economy. Diverse Approaches and Practices in Europe and Canada. In: OECD/OCDE, The Social Economy as a Tool of Social Innovation and Local Development. Background Report. Paris, OECD/OCDE et LEED, pp.125-173, 2005.

LE GALÈS, P. (Dir.). Gouvernement et gouvernance des territoires. Problèmes politiques et sociaux, La Documentation française, No 922, 2006.

LÉVESQUE, B. Développement local au Québec, 20 ans d'expérimentation et d'institutionnalisation. In: ITÇAINA, X. PALARD, J. \& SÉGAS, S. (Dir.). Régimes territoriaux et développement économique. Rennes: Presses universitaires de Rennes, 2007.

LÉVESQUE, B. Le modèle québécois : un horizon théorique pour la recherche, une porte d'entrée pour un projet de société? In: Alternatives économiques, no 29, octobre 2002. [www.teluq. uquebec.ca/interventionseconomiques].

. Un nouveau paradigme de gouvernance : la relation autorité publique-marché-société civile pour la cohésion sociale/A new governance paradigm: public authorities-markets-civil society linkage for social cohesion. In: Les choix solidaires dans le marché: un apport vital à la cohésion sociale/Solidarity-based Choices in the Market-Place : a vital contribution to social cohesion, Strasbourg, Édition du Conseil de l'Europe/Council of Europe Publishing (coll.Tendances de la cohésion sociale no 14/ Trends in social cohesion, no 14), 2005.

. Le potentiel d'innovation sociale de l'économie sociale: quelques éléments de problématique. Revue Économie et Solidarités, Vol. 37, no 1, $2006 a$.

. L'innovation dans le développement économique et dans le développement social », in J.-L. Klein e D. Harrisson (Dir.). Linnovation sociale. Émergence et effet sur la transformation sociale. Québec, Presses de l'Université du Québec, 2006b.

LÉVESQUE, B.; BOURQUE, G. \& FORGUES, É. La nouvelle sociologie économique. Originalité et diversité des approches, Paris, Desclée de Brouwer, 2001.

LÉVESQUE, B. \& MENDELL, M. Diversité des definitions et des constructions théoriques. Intervention économiques, No 32, 
2005. [http://www.teluq.uquebec.ca/pls/inteco/rie.entree?vno_ revue $=1 \&$ vno_numero $=39$ ]

LIPIETZ, A. Vert espérance. L'avenir de l'écologie politique. Paris: La découverte, 1993.

. Choisir l'audace. Une alternative pour le XXIe siècle, Paris, La Découverte, 1989.

LUNDVALL, B.A. (Dir.) National System of Innovation. Toward a Theory of Innovation and Interactive Learning, London et New York, 1992.

MALO, M.C. La gestion stratégique de la coopérative et de l'association d'économie sociale. Revue internationale de l'économie sociale (RECMA), Première partie, No 281, deuxième partie; No 282, 2001.

MALO, M.C. \& VÉZINA, M. Gouvernance et gestion de l'entreprise collective d'usagers : stratégie de création de valeur et configuration organisationnelle. Économie et solidarités, Vol. 35 no 1, 2004.

MARÉCHAL, J.P. De la religion de la croissance à l'exigence de développement durable. In: MARÉCHAL, J.P. \& QUENAULT, B. (Dir.), Le développement durable. Une perspective pour le XXIe siècle. Rennes: Presses Universitaire de Rennes, 2005a.

. Développement durable ", in J.-L. LAVILLE e A. D. CATTANI (Dir), Dictionnaire de l'autre économie, Paris, Desclée de Brouwer, pp. 125-133, 2005b

MATZNER, E. \& STREECK, W. Beyond Kenesianism. The SocioEconoics of Production and Full Employment. Aldershot: Edwared Elgar Publishing Limited, 1991.

MONNIER, L. \& THIRY, B. Architecture et dynamique de l'intérêt général. In: MONNIER, L. \& THIRY, B. (Dir.) Mutations structurelles et intérêt general. Vers quels nouveaux paradigms pour l'économie publique, sociale et cooperative. Bruxelles: De Boeck-Université, 1997.

NELSON, R., \& WINTER, S. National Systems of Innovation: A Comparative Study. Oxford: University Press, 1982.

PASQUERO, J. La responsabilité sociale de l'entreprise comme objet des sciences de gestion : le concept et sa portée . TURCOTTE, M.F. 
\& SALMON, A. Responsabilité sociale et environnementale de l'entreprise. Québec: PUQ, pp. 112-143, 2005.

PASSET, R. Conclusion - Néolibéralisme ou développement durable: il faut choisir. MARÉCHAL, J.-P. \& QUENAULT, B. (Dir.) Le développement durable. Une perspective pour le XXIe siècle. Rennes: Presses Universitaire de Rennes, 2007.

PECQUEUR, B. Le tournant territorial de la globalisation. In: ITÇAINA, X., PALARD, J. \& SÉGAS, S. (Dir.) Régimes territoriaux et développement économique. Rennes: Presses Universitaires de Rennes, 2007.

Le développement local pour une économie des territoires. Paris: Syros, 2000.

PESTOFF, V.A. Beyond the Market and State - Social entreprises and civil democracy in a welfare society. Ashgate, Aldershot, 1998.

PINSON, G. Interactions et délibérations : vertus des nouvelles formes d'action. In: LE GALÈS, P. (Dir.). Gouvernement et gouvernance des territoires, Problèmes politiques et sociaux, La Documentation française, No 922, pp. 85-87, 2006.

PIORE, M. J. \& SABEL, C. Les chemins de la prospérité. De la production de masse à la spécialisation souple. Paris: Hachette (Première édition en anglais : The Second Industrial Divide, 1984), 1989.

SAINTENY, G. La responsabilité sociétale des entreprises : demande de la société ou exigence du marché. In: SMOUTS, M.-C. (Dir.) Le développement durable. Les termes du débat, Paris, Armand Colin, 2005.

SALMON, A. La tentation éthique du capitalisme. Paris: La Découverte, 2007.

SCHMITTER, P.C. Interest Systems and the Consolidation of Democracies. In: MARKS, A.G. (Dir.) Reexamining Democracy. Londres: Sage Publication,1992.

SÉGAS, S. Le développement comme ressource politique: conflit autour des pays. In: BHERER, L. COLLIN, J.-P., KERROUCHE, E. \& PALLARD, J. (Dir.) Jeux d'échelle et transformation de l'État. Le gouvernement des territoires au Québec et en France. Québec: Presses de l'Université Laval, 2005. 
SCHMITTER, P.C. Interest Systems and the Consolidation of Democracies. In: MARKS, A.G. (Dir.) Reexamining Democracy. Londres: Sage, 1992.

SMOUTS, M.-C. Le développement durable: valeurs et pratiques. In: SMOUTS, M.-C. (Dir.) Le développement durable. Les termes du débat. Paris: Armand Colin, 2005.

STREECK, W. Social Institutions and Economic Performance: studies of Industrial Relations. In: Advanced Capitalist Economies. London: Sage, 1992.

STREECK, W. \& SCHMITTER, P.C. (Dir.) Private Interest Government: Beyond Market and State. London: Sage Publications.

SWEDBERG, R. Une histoire de la sociologie économique. Paris: Desclée de Brouwer, 1994 (Traduction: Economic sociology: Past and Present, Sage Publication, 1987).

THEYS, J. Le développement durable: une illusion motrice. Une innovation sous-exploitée. In: SMOUTS, M.-C. (Dir.) Le développement durable. Les termes du débat. Paris: Armand Colin, 2005.

TURCOTTE, M.-F. \& SALMON, A. Responsabilité sociale et environnementale de l'entreprise. Québec: PUQ, 2005.

VELTZ, P. Mondialisation, Villes et Territoires. L'économie en archipel. Paris, PUF, 1996.

VIENNEY, C. L'économie sociale. Paris, La Découverte (coll: Repères), 1994.

Paris: CIEM.

. Socio-économie des organisations cooperatives.

WILLIAMSON, O. E. The Economics of Organization: The Transaction Cost Approach. American Journal of Sociology, vol. 87, 1981.

ZELIZER, V. The Social Meaning of Money, Pin Money, Paychecks, Poor Relief \& Other Currencies. New York, Basic Books, 1994.

. The social meaning of money: Special monies. In: American Journal of Sociology, vol 95 no 2, 1989.

ZIMMERMANN, J.-B. Entreprises et territoires : entre nomadisme et ancrage territorial. La Revue de l'IRES, Restructuration. Nouveaux enjeux , nr. spécial, No 47, 2005/1, 2005. 


\section{Abstract \\ Plural economics and territorial development from the perspective of sustainable development: theoretical elements of an economic sociology and a socio-economics.}

This text focuses on the contribution that the concept of plural economics is able to make today toward the advancement of research on the viability of territorial dynamics for sustainable development. The first part of our line of argumentation is centered on clarifying the concept of plural economics, based on studies on economic and social solidarity and on proposals emerging from the New Economic Sociology and the socio-economics of territories. In the second part, the concept of sustainable development is characterized from the angle of the so-called societal paradigm and its interactions with territory and with a plural and social economics. Aligned with the critique of the premises of neo-classical economics, the author accepts the need to re-connect the economy to a broader social and ecological perspective and to seek more effective answers to the challenges raised by the planetary socio-environmental crisis..

Keywords: Sustainable territorial development, plural economics, New Economic Sociology, economics of solidarity, ecological economics. 